\title{
Is there justification for prophylactic extraction of third molars? A systematic review
}

\section{Moacir Guilherme da Costa ${ }^{(a)}$ Camila Alessandra Pazzini(b) Mariele Cristina Garcia Pantuzo(a) Maria Letícia Ramos Jorge ${ }^{(c)}$ Leandro Silva Marques ${ }^{(c)}$}

(a) Department of Orthodontics, School of Dentistry, Univ Vale do Rio Verde - UninCor, Três Corações, MG, Brazil.

(b) Department of Orthodontics, School of Dentistry, Univ Federal de Minas Gerais UFMG Belo Horizonte, MG, Brazil.

(c)Department of Pediatric Dentistry, School of Dentistry, Univ Federal dos Vales do Jequitinhonha e Mucuri - UFVJM, Diamantina, MG, Brazil.
Declaration of Interests: The authors certify that they have no commercial or associative interest that represents a conflict of interest in connection with the manuscript.

Corresponding Author: Leandro Silva Marques Email: Ismarques.prof@gmail.com

Submitted: Aug 31, 2012

Accepted for publication: Dec 13, 2012 Last revision: Dec 13, 2012

\begin{abstract}
The present systematic review was performed to investigate if there is evidence justifying the prophylactic extraction of third molars, one of the most frequent procedures in oral surgery. A series of searches was carried out for randomized, clinical trials and systematic reviews in seven databases (MEDLINE, BBO, LILACS, Web of Science, EMBASE, BIREME and Cochrane Library), with no restrictions regarding year or language. A supplemental manual search of the references of retrieved articles was also performed. The search strategy resulted in 260 papers. Both the data extracted and the quality of each paper were evaluated independently by two reviewers. After selection based on the preestablished eligibility criteria, four papers qualified for the final analysis. A medium degree of quality and methodological consistency was found in three studies, and low quality was found in one study. No studies showed a high degree of consistency. The most significant flaw was an inadequate sample size. The results of the present review indicate a lack of scientific evidence to justify the indication of the prophylactic extraction of third molars.
\end{abstract}

Descriptors: Tooth Extraction; Molar, Third; Pathology; Crowding.

\section{Introduction}

Third molar extraction is one of the most frequent procedures in oral surgery. Ten million teeth are extracted from approximately five million individuals every year in the United States alone, with an annual cost of over US $\$ 3$ billion. ${ }^{1}$ In England and Wales, expenditures on prophylactic extractions between 1995 and 1996 amounted to approximately $£ 5.2$ million. ${ }^{2}$ The reason for these extractions is the high incidence of impaction, often associated with a number of oral problems, such as pericoronitis, periodontal defects in the distal region of the second molar, caries in the third or second molars, different types of odontogenic cysts and tumors, and crowding of the lower incisors. ${ }^{3-6}$

Although a number of studies have been published on third molar extraction, the conflicting results hinder the decision-making process. The controversies are related to inadequate study designs, small sample size, insufficient monitoring time and methodological flaws. ${ }^{3-28}$

The aim of the present study was to perform a systematic review of the literature, to discuss consensual aspects and controversies related to third molar extraction, and to answer the following question: Is there 
evidence to justify the prophylactic extraction of third molars?

\section{Methodology Search strategy}

A series of searches was performed for texts published up to August 30, 2012, with no restrictions regarding language, age, gender or date of publication. The following key words were used:

- "asymptomatic impacted third molar,"

- "pericoronitis,"

- "periodontal problems, third molar,"

- "complication asymptomatic third molar,"

- "impacted third molar complications,"

- "third molar, surgery, causes," and

- "extraction of third molars, crowding lower jaw.”

The following databases were searched:

- Latin American and Caribbean Center on Health Sciences Information - BIREME (www. bireme.br): Lilacs (Literature in Health Sciences published in Latin America and the Caribbean since 1982), Medline via OVID (International Medical and Biomedical Literature, compiled since 1965), and EMBASE via OVID.

- Web of Science (www.thomsonisi.com): database of sciences, social sciences, arts and humanities;

- Cochrane Library: access to databases on systematic reviews of controlled studies of the Cochrane Collaboration, evaluation of health technologies, Cochrane Oral Health Group's Trials Register; the Cochrane Central Register of Controlled Trials (CENTRAL); BBO (Brazilian Bibliography of Dentistry).

A series of manual searches was also performed, based on the lists of references of the articles retrieved from the different databases. Data were collected on author, year of publication, study design, study groups, methods/measures and results. A quality assessment of preestablished characteristics was performed, to document the methodological strength of each paper. ${ }^{11,12}$ The eight variables investigated in the quality assessment are listed in Table 1 .
Sample size was considered adequate when the sample size calculation was presented. Measurement methods were considered valid when a measurement error test was presented. Each study was classified based on the scores attributed:

- low quality (0 to 5 points),

- medium quality (6 to 8 points) or

- high quality (9 to 10 points).

Data extraction and the quality assessment of each paper were performed independently by two researchers, who selected papers based on a reading of the title and the abstract. All papers that appeared to meet the eligibility criteria were selected. A high level of agreement between the researchers was found in this step. A manual search of the reference lists from the selected papers was also performed to obtain additional relevant publications that might have been missed in the database searches.

\section{Selection criteria}

Only randomized controlled clinical trials and systematic reviews addressing the main indications, the effect of prophylactic third molar extraction and the non-intervention (maintenance) of asymptomatic impacted third molars were selected for the present review (Table 2).

Table 1 - Scores used for quality analysis of papers selected.

\begin{tabular}{l|c}
\hline $\begin{array}{l}\text { Adequate study } \\
\text { design }\end{array}$ & $\begin{array}{l}\text { Randomized clinical trial, prospective } \\
\text { study, controlled clinical trial, } \\
\text { longitudinal study: 3 points; } \\
\text { Clinical trial: 1 point }\end{array}$ \\
\hline Adequate sample size & 1 point \\
\hline $\begin{array}{l}\text { Adequate description } \\
\text { of selection process }\end{array}$ & 1 point \\
\hline $\begin{array}{l}\text { Valid measurement } \\
\text { methods }\end{array}$ & 1 point \\
\hline $\begin{array}{l}\text { Use of method of } \\
\text { error analysis }\end{array}$ & 1 point \\
\hline $\begin{array}{l}\text { Blinded measurement } \\
\text { evaluation }\end{array}$ & 1 point \\
\hline $\begin{array}{l}\text { Valid statistical } \\
\text { methods }\end{array}$ & 1 point \\
\hline $\begin{array}{l}\text { Confounding factors } \\
\text { included in analysis }\end{array}$ & 1 point \\
\hline
\end{tabular}




\section{Data acquisition and analysis}

Data were collected on conditions that could indicate the prophylactic extraction of impacted third molars:

- pericoronitis,

- caries and periodontal problems in the distal region of the second molars,

- odontogenic cysts and tumors, and

- crowding of the lower incisors.

\section{Results}

The search strategy yielded 260 papers. Four studies qualified for the final analysis (Table 3), following a selection based on the preestablished eligibility criteria. The complete texts of these papers were obtained for analysis.

\section{Quality of the studies}

A medium degree of quality and methodological consistency was found in three studies and low quality was found in one study (Table 4). No studies showed a high degree of consistency. The most significant flaw was an inadequate sample size. Other flaws included the failure to declare the blinded assessment of the measurements and confounding fac-

Table 2 - Initial inclusion and exclusion criteria for the studies retrieved.

\begin{tabular}{l|l}
\hline \multicolumn{1}{c|}{ Inclusion criteria } & \multicolumn{1}{c}{ Exclusion criteria } \\
\hline - Randomized controlled & - Case reports and \\
trials, systematic review & case series \\
and meta-analyses & - Review articles and \\
- All languages & abstracts \\
\hline
\end{tabular}

Table 3 - Studies selected.

\begin{tabular}{|c|c|c|c|c|c|}
\hline Author & Study groups & Sample & Age & Measurement method & Results \\
\hline $\begin{array}{l}\text { Mettes } \\
\text { et al. } \\
(2005)^{27}\end{array}$ & $\begin{array}{l}\text { Systematic review assessing } \\
\text { the effect of prophylactic } \\
\text { extraction of third molars } \\
\text { in adolescents and adults, } \\
\text { in comparison to non- } \\
\text { intervention }\end{array}$ & - & - & $\begin{array}{l}\text { Searches in Medline } \\
\text { and Cochrane } \\
\text { through August 4, } \\
2004 \text {; randomized or } \\
\text { controlled clinical trials } \\
\text { were selected }\end{array}$ & $\begin{array}{l}\text { No evidence was found to } \\
\text { support or refute the routine } \\
\text { prophylactic extraction of } \\
\text { asymptomatic impacted third } \\
\text { molars }\end{array}$ \\
\hline $\begin{array}{l}\text { Van der } \\
\text { Sanden } \\
\text { et al. } \\
(2005)^{26}\end{array}$ & $\begin{array}{l}\text { Dental students who received } \\
\text { a clinical practice guide } \\
\text { for the management of } \\
\text { asymptomatic third molars }\end{array}$ & $\begin{array}{l}36 \text { impacted } \\
\text { lower third molars; } \\
102 \text { students } \\
\text { participated in } \\
\text { the study ( } 51 \text { in } \\
\text { each group_-test } \\
\text { and control); } \\
\text { randomized } \\
\text { selection }\end{array}$ & $\begin{array}{l}\text { Three age } \\
\text { groups: } \\
19-25, \\
26-40 \text { and } \\
41-60 \text { years }\end{array}$ & $\begin{array}{l}\text { The intervention and } \\
\text { control groups received } \\
\text { a questionnaire, and the } \\
\text { data were submitted to } \\
\text { analysis of co-variance } \\
\text { and the chi-square test }\end{array}$ & $\begin{array}{l}\text { The use of a clinical practice } \\
\text { guide for the management } \\
\text { of asymptomatic third molars } \\
\text { is effective and enhances the } \\
\text { decision-making process for } \\
\text { dental surgeons }\end{array}$ \\
\hline $\begin{array}{l}\text { Harradine } \\
\text { et al. } \\
(1998)^{22}\end{array}$ & $\begin{array}{l}\text { Randomized allocation of } \\
\text { post-treatment orthodontic } \\
\text { patients submitted to } \\
\text { extraction of lower third } \\
\text { molars to monitor the effect } \\
\text { of the extractions on crowding } \\
\text { of the lower incisors }\end{array}$ & $\begin{array}{l}\text { Total of } 164 \\
\text { ( } 90 \text { women and } \\
74 \text { men) }\end{array}$ & $\begin{array}{l}14 \text { years } \\
\text { and } 10 \\
\text { months for } \\
\text { participation } \\
\text { in the study, } \\
\text { with } 66 \\
\text { months of } \\
\text { follow-up }\end{array}$ & $\begin{array}{l}\text { Patients were allocated } \\
\text { based on a list, and } \\
\text { were contacted after } \\
5 \text { years. Models } \\
\text { were constructed, } \\
\text { measurements were } \\
\text { made and data were } \\
\text { submitted to the } \\
\text { Minitab program and } \\
\text { GLIM statistical software }\end{array}$ & $\begin{array}{l}\text { No significant differences in } \\
\text { lower incisor crowding were } \\
\text { found between patients from } \\
\text { whom third molars were } \\
\text { extracted and those on whom } \\
\text { no intervention was performed; } \\
\text { thus, the prophylactic } \\
\text { extraction of third molars is not } \\
\text { justified }\end{array}$ \\
\hline $\begin{array}{l}\text { Lindqvist } \\
\text { and } \\
\text { Thilander } \\
(1982)^{23}\end{array}$ & $\begin{array}{l}\text { Randomized allocation } \\
\text { of patients submitted to } \\
\text { extraction of third molars } \\
\text { removed on one side and } \\
\text { maintained on the other side } \\
\text { (control); after three years, } \\
\text { radiographs were taken and } \\
\text { study models were made }\end{array}$ & $\begin{array}{l}23 \text { boys and } 29 \\
\text { girls with impacted } \\
\text { third molars on } \\
\text { both sides of the } \\
\text { mandible }\end{array}$ & $\begin{array}{l}15.5 \text { years; } \\
\text { range: } 13 \text { to } \\
19 \text { years }\end{array}$ & $\begin{array}{l}\text { Radiographs and study } \\
\text { models }\end{array}$ & $\begin{array}{l}\text { No conclusions were made } \\
\text { regarding which patients } \\
\text { should undergo the anticipated } \\
\text { extraction of third molars } \\
\text { to prevent late crowding; } \\
\text { however, in cases of severe } \\
\text { crowding, third molar } \\
\text { extraction may be indicated }\end{array}$ \\
\hline
\end{tabular}


Table 4 - Quality evaluation of the studies retrieved.

\begin{tabular}{|c|c|c|c|c|c|c|c|c|c|}
\hline Articles & $\begin{array}{l}\text { Study } \\
\text { design }\end{array}$ & Sample size & $\begin{array}{c}\text { Selection } \\
\text { description }\end{array}$ & $\begin{array}{c}\text { Valid } \\
\text { measurement } \\
\text { methods }\end{array}$ & $\begin{array}{l}\text { Method } \\
\text { of error } \\
\text { analysis }\end{array}$ & $\begin{array}{l}\text { Blinding in } \\
\text { measurement }\end{array}$ & $\begin{array}{l}\text { Adequate } \\
\text { statistics } \\
\text { provided }\end{array}$ & $\begin{array}{l}\text { Confounding } \\
\text { factors } \\
\text { considered }\end{array}$ & $\begin{array}{c}\text { Quality } \\
\text { standard } \\
\text { judgement }\end{array}$ \\
\hline $\begin{array}{l}\text { Mettes et al. } \\
(2005)^{27}\end{array}$ & RCT & Inadequate & Adequate & Yes & No & No & No & ND & Low \\
\hline $\begin{array}{c}\text { Van der } \\
\text { Sanden et al. } \\
(2005)^{26}\end{array}$ & RCT & Inadequate & Adequate & Yes & No & ND & Yes & ND & Medium \\
\hline $\begin{array}{l}\text { Harradine } \\
\text { et al. (1998) }\end{array}$ & $\mathrm{RCT} / \mathrm{P}$ & Inadequate & Adequate & Yes & Yes & ND & Yes & ND & Medium \\
\hline $\begin{array}{l}\text { Lindqvist and } \\
\text { Thilander } \\
(1982)^{23}\end{array}$ & RCT & Inadequate & Adequate & Yes & No & No & Yes & ND & Medium \\
\hline
\end{tabular}

CCT: controlled clinical trial; RCT: randomized clinical trial; CT: clinical trial; L: longitudinal; P: prospective; ND: not declared.

tors. Only one paper adequately described the method of error analysis.

\section{Discussion}

None of the studies fulfilled the eligibility criteria established for the present systematic review. This finding demonstrates the scarcity of consistent papers and inadequate scientific evidence that could otherwise allow surgeon dentists to make decisions regarding reliable indications for the prophylactic extraction of third molars and the determination of which cases should be followed up. Meta-analysis and heterogeneity were not performed due to the small number of studies with different methodologies found.

The prophylactic extraction of asymptomatic impacted wisdom teeth is defined as the (surgical) removal of wisdom teeth in the absence of local disease. ${ }^{28}$ In this context, critical appraisal of the literature reveals that prophylactic extraction of third molars occurs in a disorderly manner without clearly defined criteria. Approximately $75 \%$ of individuals who receive regular dental care have their third molars removed. ${ }^{4}$ In addition to the pathological conditions sometimes caused by these teeth, other criteria are used to justify the decision to extract, including indications for orthodontic, prosthetic or restorative purposes. ${ }^{13,14}$ Moreover, the risks of surgery and associated complications are justified and uniformly accepted by the majority of dental surgeons, when there is clinical, radiological or laboratorial evidence of acute or chronic periodontitis, caries, pericoronitis, harmful effects on second molars or disease..$^{15,16}$

Authors enumerate the main reasons leading to the prophylactic extraction of third molars, but these indications do not have sufficient evidence on which to base such a decision. ${ }^{3-6}$ Partially erupted third molars have the greatest likelihood of developing pericoronitis, and are therefore indicated for prophylactic extraction. ${ }^{9} 10$ Mohammed-Ali et al. ${ }^{17}$ report two cases of osteomyelitis in the mandible, with development secondary to pericoronitis in partially erupted third molars. McArdle and Renton ${ }^{18}$ indicate the prophylactic extraction of third molars for the prevention of caries on the distal face of the second molars. According to Allen et al. ${ }^{19}$, it is common to find caries on the distal surface of second molars when third molars are either completely or partially erupted. Should conservative treatment be elected, interproximal radiographs are recommended.

Kan et al. ${ }^{8}$ justifies prophylactic extraction in cases of periodontal defects. However, Richardson and Dodson ${ }^{20}$ state that the indication for third molar extraction should be evaluated carefully in individuals with a healthy periodontium in the region of the second molar, since this procedure heightens the risk of greater probing depth and attachment loss. The extraction of lower third molars could lead to periodontal defects in the distal region of the adjacent second molar. ${ }^{21}$

Harradine et al. ${ }^{22}$ conclude that the extraction of 
third molars to reduce or prevent late crowding of the incisors is not justified, and should therefore not be considered as having a scientific basis. Likewise, Lindqvist and Thilander ${ }^{23}$ evaluated adolescents with non-erupted third molars, and could not predict which patients would benefit and which would suffer negative consequences in regard to late crowding following extraction of impacted third molars.

The consequences of extraction for patients should also be analyzed. Song et al. ${ }^{2}$ suggest that a "wait-and-see conduct" could be a promising strategy. Jerjes et al. ${ }^{24}$ enumerated postoperative complications stemming from third molar extractions performed by residents and specialists; trismus, alveolar osteitis and paresthesia of the lingual and inferior alveolar nerves were reported among extractions performed by residents, and postoperative bleeding was reported among extractions performed by specialists.

Countries such as the United States and the United Kingdom spend large amounts of money on these procedures annually, using funds that could otherwise be spent on other health programs. ${ }^{1,2}$ The extraction of asymptomatic impacted third molars that could remain disease-free for an undetermined amount of time places an unnecessary burden on healthcare funds. The assessment of health risks and cost effectiveness regarding the prophylactic extraction of asymptomatic impacted wisdom teeth should play a more prominent role in the decision-making process. $^{25}$

Insecurity in making diagnosis and the lack of a protocol for the extraction or non-extraction of third molars are clearly demonstrated. ${ }^{26}$ When a clinical practice guide was given to dentists, a drastic reduction in the number of indications for extraction occurred. In other words, when dentists have a

\section{References}

1. Friedman JW. The prophylactic extraction of third molars: a public health hazard. Am J Public Health. 2007 Sep;97(9):1554-9.

2. Song F, O'Meara S, Wilson P, Golder S, Kleijnen J. The effectiveness and cost effectiveness of prophylactic removal of wisdom teeth. Health Technol Assess. 2000 Jul;4(15):1-55. greater scientific foundation, they modify how they conduct themselves in the decision-making process from a clinical standpoint. Further studies on this issue are eagerly awaited, insofar as dental surgeons should base their justifications for prophylactic third-molar extractions on scientific evidence and studies that can reliably clarify indications for extraction or non-intervention. ${ }^{27}$

The clinical implications of how asymptomatic impacted third molars should be handled were well described by Mettes et al. ${ }^{27}$ :

\footnotetext{
"The dental clinician, who examines healthy individuals in the course of assigning a recall interval, should be responsible for monitoring third molars in recurrent communication with patients and, where there are more complex cases, with the oral and maxillofacial surgeon as a consultant. Special attention should be paid to the onset of pathology, based on explicit terminology and definitions, the monitoring and registration of morbidity and quality of life aspects (i.e. patients' perspective, values and attitudes). Clinicians should make it clear to adult patients with asymptomatic third molars that there is no evidence one way or the other about the benefits or otherwise of removing these molars. The same communication strategy to adolescents and their parents regarding the impact of surgical removal on late lower incisor crowding should be advocated."
}

\section{Conclusions}

The data encountered in the present systematic review demonstrate the lack of studies on which to base adequate clinical decisions regarding indications for the prophylactic extraction of third molars. The only scientific proof points to the non-indication of prophylactic extraction for the purpose of preventing late crowding of the lower incisors.

3. Laskin DM. Evaluation of the third molar problem. J Am Dent Assoc.1971 Apr;82(4):824-8.

4. Schulhof RJ. Third molars and orthodontic diagnosis. J Clin Orthod. 1976 Apr;10(4):272-81.

5. Lysell L, Rohlin M. A study of indications used for removal of the mandibular third molar. Int J Oral Maxillofac Surg. 1988 Jun;17(3):161-4. 
6. Stanley HR, Alattar M, Collett WK, Stringfellow HR Jr, Spiegel EH. Pathological sequelae of "neglected" impacted third molars. J Oral Pathol. 1988 Mar;17(3):113-7.

7. McArdle LW, Renton TF. Distal cervical caries in the mandibular second molar: an indication for the prophylactic removal of the third molar?. Br J Oral Maxillofac Surg. 2006 Feb;44(1):42-5.

8. Kan KW, Liu JK, Lo EC, Corbet EF, Leung WK. Residual periodontal defects distal to the mandibular second molar 6-36 months after impacted third molar extraction. J Clin Periodontol. 2002 Nov;29(11):1004-11.

9. Wang XL. [Correlation study on acute pericoronitis and the position of the mandibular impacted third molar]. Shanghai Kou Qiang Yi Xue. 1995 Jun;4(2):70-2. Chinese.

10. Yamalik K, Bozkaya S. The predictivity of mandibular third molar position as a risk indicator for pericoronitis. Clin Oral Investig. 2008 Mar;12(1):9-14.

11. Antczak AA, Tang J, Chalmers TC. Quality assessment of randomized control trials in dental research I. Methods. J Periodontal Res. 1986 Jul;21(4):305-14.

12. Jadad AR, Moore RA, Carroll D, Jenkinson C, Reynolds DJ, Gavaghan DJ, McQuay HJ. Assessing the quality of reports of randomized clinical trials: is blinding necessary?. Control Clin Trials. 1996 Feb;17(1):1-12.

13. Chaparro-Avendaño AV, Pérez-García S, Valmaseda-Castellón E, Berini-Aytés L, Gay-Escoda C. Morbidity of third molar extraction in patients between 12 and 18 years of age. Med Oral Patol Oral Cir Bucal. 2005 Nov-Dec;10(5):422-31.

14. Kruger E, Thomson WM, Konthasinghe P. Third molar outcomes from age 18 to 26: findings from a population-based New Zealand longitudinal study. Oral Surg Oral Med Oral Pathol Oral Radiol Endod. 2001 Aug;92(2):150-5.

15. Marciani RD. Third molar removal: an overview of indications, imaging, evaluation, and assessment of risk. Oral Maxillofac Surg Clin North Am. 2007 Feb;19(1):1-13.

16. Bagheri SC, Khan AH. Extraction versus nonextraction management of third molars. Oral Maxillofac Surg Clin North Am. 2007 Feb;19(1):15-21.

17. Mohammed-Ali RI, Collyer J, Garg M. Osteomyelitis of the mandible secondary to pericoronitis of an impacted third molar. Dent Update. 2010 Mar;37(2):106-8.

18. McArdle LW, Renton TF. Distal cervical caries in the mandibular second molar: an indication for the prophylactic re- moval of the third molar?. Br J Oral Maxillofac Surg. 2006 Feb;44(1):42-5.

19. Allen RT, Witherow H, Collyer J, Roper-Hall R, Nazir MA, Mathew G. The mesioangular third molar-to extract or not to extract? Analysis of 776 consecutive third molars. Br Dent J. 2009 Jun 13;206(11):586-7.

20. Richardson DT, Dodson TB. Risk of periodontal defects after third molar surgery: An exercise in evidence-based clinical decision-making. Oral Surg Oral Med Oral Pathol Oral Radiol Endod. 2005 Aug;100(2):133-7.

21. Sammartino G, Tia M, Bucci T, Wang HL. Prevention of mandibular third molar extraction-associated periodontal defects: a comparative study. J Periodontol. 2009 Mar;80(3):389-96.

22. Harradine NW, Pearson MH, Toth B. The effect of extraction of third molars on late lower incisor crowding: a randomized controlled trial.Br J Orthod. 1998 May;25(2):117-22.

23. Lindqvist B, Thilander B. Extraction of third molars in cases of anticipated crowding in the lower jaw. Am J Orthod. 1982 Feb;81(2):130-9.

24. Jerjes W, Upile T, Nhembe F, Gudka D, Shah P, Abbas S, et al. Experience in third molar surgery: an update. Br Dent J. 2010 Jul 10;209(1):E1.

25. Edwards MJ, Brickley MR, Goodey RD, Shepherd JP. The cost, effectiveness and cost- effectiveness of removal and retention of asymptomatic, disease free third molars. Br Dent J. 1999 Oct 9;187(7):380-4.

26. Van der Sanden WJ, Mettes DG, Plasschaert AJ, Grol RP, Mulder J, Verdonschot EH. Effectiveness of clinical practice guideline implementation on lower third molar management in improving clinical decision-making: a randomized controlled trial. Eur J Oral Sci. 2005 Oct;113(5):349-54.

27. Mettes TG, Nienhuijs ME, Van der Sanden WJ, Verdonschot $\mathrm{EH}$, Plasschaert AJ. Interventions for treating asymptomatic impacted wisdom teeth in adolescents and adults. Cochrane Database Syst Rev. 2005 Apr;18(2):CD003879.

28. Mettes TG, Ghaeminia H, Nienhuijs ME, Perry J, Van der Sanden WJ, Plasschaert AJ. Surgical removal versus retention for the management of asymptomatic impacted wisdom teeth. Cochrane Database Syst Rev. 2012 Jun 13;6:CD003879. doi: 10.1002/14651858.CD003879.pub3. 